\title{
ALMADA - O Desvendar da Arte da Pintura Mural de Almada Negreiros (1938-1956)
}

\section{Vasco Bonifácio}

vasco.bonifacio@tecnico.ulisboa.pt $\bullet \bullet \bullet$

O projeto ALMADA tem como foco principal o estudo das técnicas pictóricas e materiais empregues pelo artista nas suas pinturas murais entre 1938 e 1956. Apesar das pinturas murais realizadas em Lisboa constarem entre as mais emblemáticas obras-primas da Arte Moderna Europeia, o conhecimento das suas características técnicas e materialidade é ainda limitado. Na base desta investigação está uma combinação de História da Arte, História Técnica da Arte e Ciências do Património Cultural. 0 projeto do Laboratório HERCULES da Universidade de Évora oferece uma alargada investigaç̧ão transdisciplinar com parceiros que contribuirão, na sua área de especialização, para explorar e divulgar os métodos de trabalho de Almada Negreiros. O projeto assenta em três abordagens: i) Investigação de história de arte e história das técnicas da produção artística com recolha e avaliação de documentação e sua integração com os resultados obtidos dos exames de superfície e caracterização material; ii) Exames de superfície das pinturas com recurso a técnicas convencionais e avançadas de imagem no visível, ultravioleta e infravermelho; iii) Caracterização material conjugando técnicas de análise in loco não invasivas (colorimetria, espectrofotometria no visível, FORS, espectrometria de fluorescência de raios-X), com técnicas microscópicas e analíticas avançadas em laboratório (microscopia ótica; microscopia eletrónica de varrimento; $\mu$-FTIR; $\mu$-Raman; $\mu$-DRX, LC-MS, py-GC-MS).

Os objetivos são a identificação das técnicas pictóricas e caracterização química, elementar e mineralógica dos materiais constituintes do suporte e das camadas cromáticas até hoje desconhecidos e apuramento de suas potenciais implicações nos fenómenos de deterioração registados ao longo destes últimos 30 anos para a sua futura salvaguarda e manutenção.
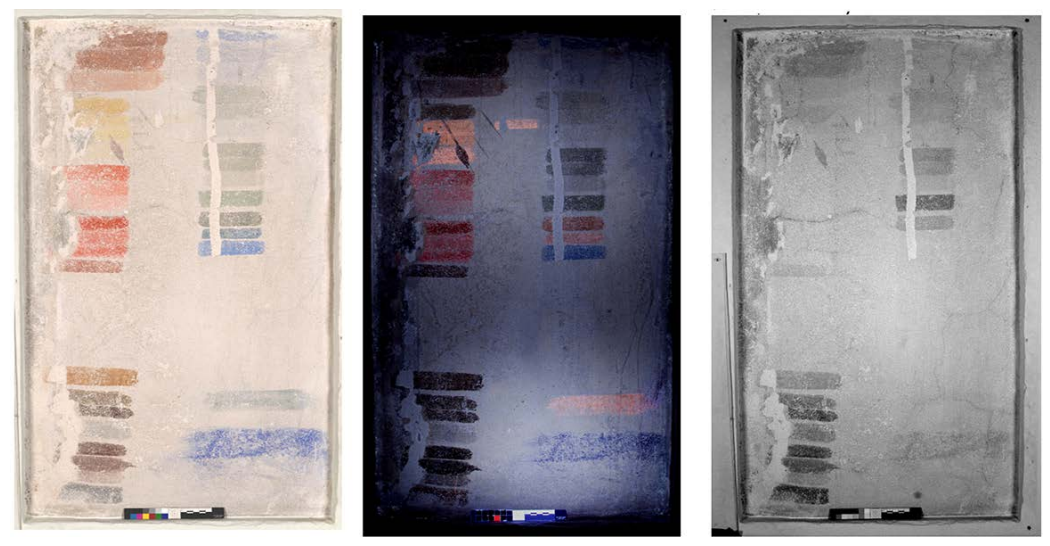

Paleta de Almada Negreiros

observada com luz visível, com luz

ultravioleta e no infravermelho próximo

$(1000 \mathrm{~nm})$ (da esquerda para a direita).

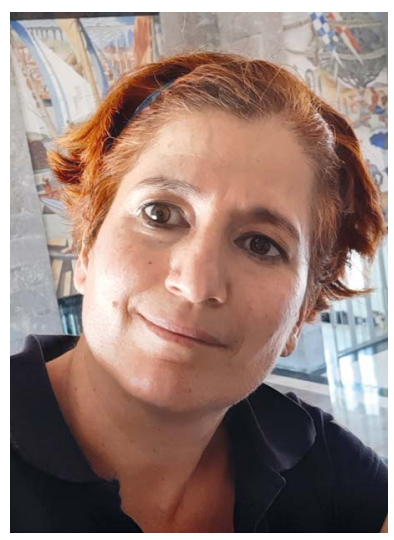

Ficha Técnica do projeto

\section{Milene Gil}

Referência: PTDC/ART-HIS/1370/2020.

Financiamento: $F C T$, através de fundos nacionais $\mathrm{OE}$. Equipa: Lab. HERCULES/UE - Milene Gil (IR), António Candeias (Co-IR), Ana Manhita, Ana Cardoso, Carlo Bottaini, Cristina Dias, Sara Valadas; DGPC - Gabriela de Carvalho, Irene Frazão, Michèle Portela; FCSH/UM - Mariana Pinto dos Santos; APL - Sara Charneca.

URL: https://almadanegreiros.uevora.pt

Vídeo: https://www.youtube.com/watch?v=dyFAn6b0R9o 